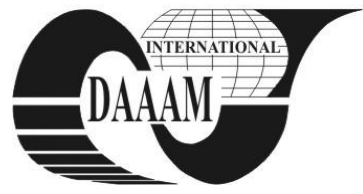

Annals of DAAAM for 2011 \& Proceedings of the 22nd International DAAAM Symposium, Volume 22, No. 1, ISSN 1726-9679 ISBN 978-3-901509-83-4, Editor B. Katalinic, Published by DAAAM International, Vienna, Austria, EU, 2011 Make Harmony between Technology and Nature, and Your Mind will Fly Free as a Bird Annals \& Proceedings of DAAAM International 2011

\title{
PLASMA ARC WELDING OF STEEL SHEETS TREATED BY NITROOXIDATION
}

\author{
MICHALEC, I[van] \& MARONEK, M[ilan]
}

\begin{abstract}
Nitrooxidation is a non-conventional thermochemical treatment which significantly increases the mechanical properties as well as the corrosion resistance of the steel sheat. The paper deals with the welding possibility of this type of treated steel sheets by a plasma arc welding. Elimination of the porosity, most common issue of materials treated by nitrooxidation, was achieved. On the other hand, undercuts were observed

Key words: nitrooxidation, plasma arc welding, undercuts
\end{abstract}

\section{INTRODUCTION}

The welding of surface treated steels is a challenge for all welding specialists, due to the surface layer exposing to a strong thermal affect by the welding process (Marônek et al., 2011).

Nitrooxidation is a non-conventional thermochemical treatment. It consists of surface nitridation with subsequent oxidation. The base material acquires maximum corrosion resistance (level 10) in comparison to materials without nitrooxidation. Mechanical properties, such as yield strength, microhardness and wear resistance are also improved as well (Babul et al., 2008, Dománková et al., 2011).

From previous outcomes (Michalec et al. 2010), several arc and beam welding methods were tested with unsatisfactory results. The most common problems were the weld bead irregularity, spatter, surface layer damage in the heat affected zone (HAZ) and excessive amount of porosity, which was the main issue in each welding method. Only the solid-state laser beam welding was considered as the most suitable method, due to superior defects-free weld quality, $100 \%$ repeatability and very narrow HAZ (Bárta, 2010).

In regard to high initial costs of the laser beam welding equipment, there was a supposion, that the plasma arc welding could be an appropriate substitution, mainly due to narrow HAZ, limited thermal input and a good weld quality (Michalčaková, 2011).

\section{MATERIALS AND METHODS}

The material used for the experiments was thin steel sheet DC 01/DIN EN 10130-9 of $1 \mathrm{~mm}$ thickness. The chemical composition is reffered in Table 1. The base material (BM) was put through the process of nitrooxidation, which consisted of nitridation in environment of $\mathrm{Al}_{2} \mathrm{O}_{3}$ grains of $120 \mu \mathrm{m}$ in diameter wafted by gaseous ammonia. After the nitridation process, oxidation process started subsequently. Oxidation itself was carried out in a vapours of distilled water. The parameters of nitrooxidation are given in Table 2.

\begin{tabular}{|c|c|c|c|c|c|}
\hline $\begin{array}{c}\text { EN } \\
\text { Marking }\end{array}$ & $\begin{array}{c}\mathrm{C} \\
{[\%]}\end{array}$ & $\begin{array}{c}\mathrm{Mn} \\
{[\%]}\end{array}$ & $\begin{array}{c}\mathrm{P} \\
{[\%]}\end{array}$ & $\begin{array}{c}\mathrm{S} \\
{[\%]}\end{array}$ & $\begin{array}{c}\mathrm{Si} \\
{[\%]}\end{array}$ \\
\hline DC 01 & 0.12 & 0.60 & 0.045 & 0.045 & 0.1 \\
\hline
\end{tabular}

Tab. 1. Chemical composition of DC 01/DIN EN 10130-9 steel

\begin{tabular}{|l|c|c|}
\cline { 2 - 3 } \multicolumn{1}{c|}{} & Temperature $\left[{ }^{\circ} \mathrm{C}\right]$ & Time $[\mathrm{min}]$. \\
\hline Nitridation & 540 & 45 \\
\hline Oxidation & 350 & 5 \\
\hline
\end{tabular}

Tab. 2. Parameters of nitrooxidation

Experimenal actitivity was carried out at Faculty of Materials Science and Technology in Trnava. Total amount of 33 specimens with different welding parameters were welded on Fronius MagicWave 2200 with PlasmaModule 10 device. Argon 4N6 was used as a shielding as well as plasma gas.

\section{RESULTS AND ACHIEVEMENTS}

As the first step, visual inspection was done. There were identified some defects, such as lack of fusion and undercuts. The best specimens were chosen for further analysis. The macroscopic and microscopic analysis as well as microhardness measurements were performed.

The results of macroscopic analysis are presented in Fig. 1. The weld had regular shape, it had no porosity and was spatterfree. Nevertheless, undercuts were observed in whole weld length. The reasons of creating the undercuts as well as their elimination is under further investigation.

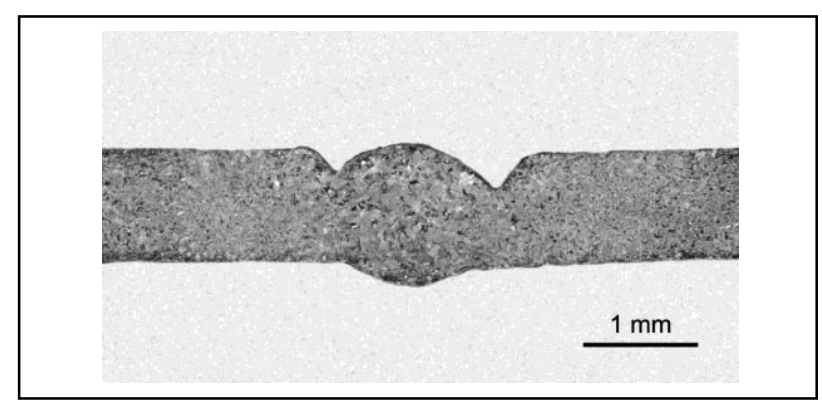

Fig. 1 Macrostructure of joint

The microscopic analysis was carried out mainly in order to obtain the information about microstructure of the weld metal (WM). In Fig. 2, it is shown, that the microstructure was composed mainly of coarse-grained acicular ferrite and polyedric ferrite as well.

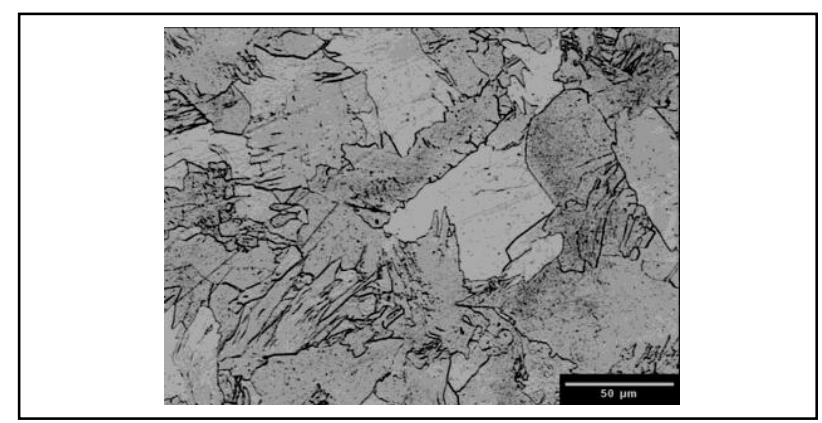

Fig. 2. Microstructure of weld metal 
Measurements according to Vickers HV0.1 with $\mathrm{F}=981 \mathrm{mN}$ of force load and $\mathrm{t}=10 \mathrm{~s}$ of loading time was carried out. The typical microhardness trend is given in Fig. 3. The highest microhardness values were observed in the weld metal, due to coarse-grained microstructure, which is in connection with the microscopic analysis. Towards to heat affected zone and base material, the microhardness values had a descending trend.

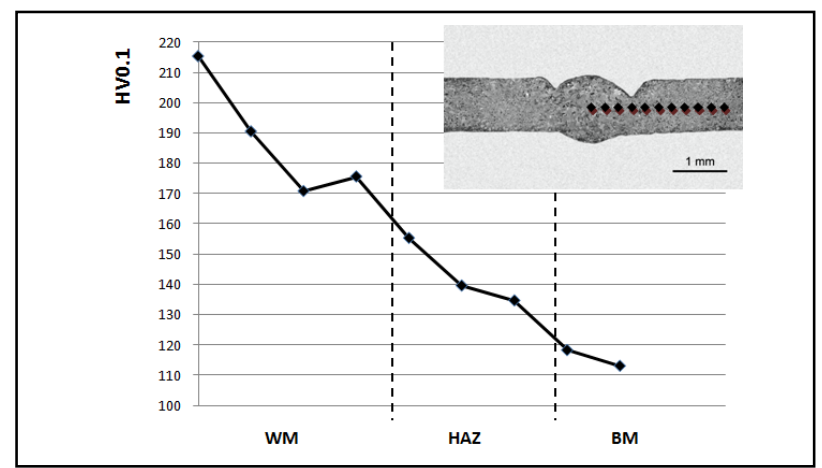

Fig. 3. Microhardness trend

The mechanical properties were evaluated by a tensile test. The main reason was to assess the joint quality regarding the presence of the undercuts.

The tensile test was carried out on four specimens with a dimensions of $100 \times 20 \times 1 \mathrm{~mm}$. The results are presented in Fig. 4. Picture shown, that the fracture area of all specimens was observed outwith the joint area and therefore the results could be marked as a suitable, not regarding the presence of the undercuts. The average force to failure was $F=6.3 \mathrm{kN}$, which represented the material tensile strength of $315 \mathrm{MPa}$.
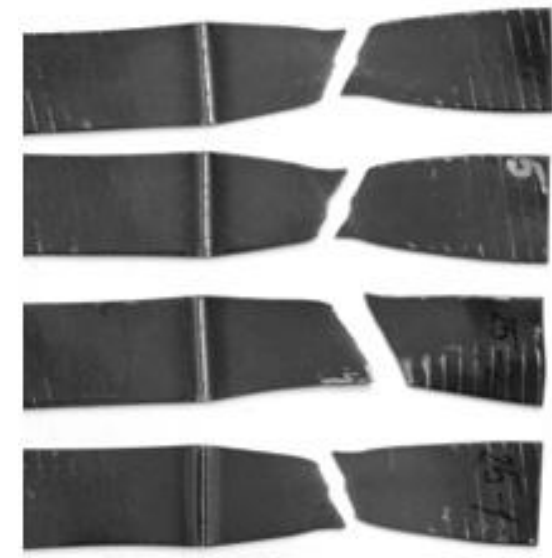

Fig. 4. Specimens after the tensile test

Because of the DC 01 steel suitilization for deep-drawing applications, Erichsen cupping test was carried out. The testing procedure was performed in accordance to STN EN 1001-5. The experimental specimens have a dimensions of $250 \times 50$ $\times 1 \mathrm{~mm}$. Total amount of three specimens were made. The results are presented in Fig. 5. The fracture character, in comparison to the joint orientation, was evaluated as the main criceria in the choice of suitability of the joints. As it is shown in Fig. 5, all tested specimens had a transverse type of the fracture both on the face and the root side of the joint. Therefore the joints were marked as a suitable regarding the fracture character.

Regarding the depth of the indent, there was an increase by $11 \%$ in comparison to the joints welded by a solid-state laser beam welding (Bárta, 2010).

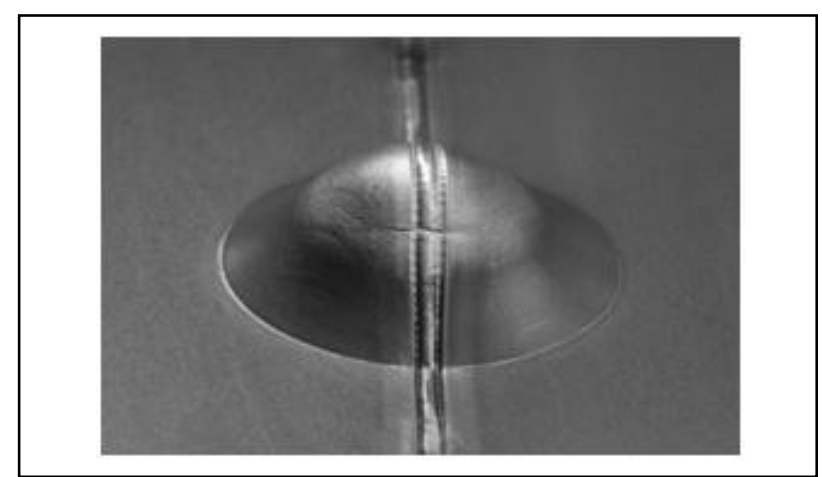

Fig. 5. Specimen after the Erichsen cupping test

\section{CONCLUSION}

Based on the previous outcomes, the laser beam welding was marked as the most suitable welding method for welding of steel sheets treated by nitrooxidation. However, the high initial cost of laser beam equipment accelerated the effort to find the other suitable welding method. The plasma arc welding, which had not been previously tested, was considered as an appropriate option.

Results showed that the elimination of porosity, which was the main issue in welding of steel sheets treated by nitrooxidation, was achieved. Mechanical properties of the joints were satisfactory as well. Nevertheless, the presence of undercuts in weld joints requires further investigation and subsequent elimination.

Therefore, the influence of a torch-to-work distance and torch-to-work angle together with change of the plasma as well as the shielding gas will be evaluated in the research to come.

\section{ACKNOWLEDGEMENTS}

This paper was prepared within the support of Slovak Research and Development Agency, grant No. 0057-07 and Scientific Grant Agency, grant No. 1/0203/11.

\section{REFERENCES}

Babul, T.; Obuchowicz, Z. \& Grzelecki, W. (2008). Nitrooxidation of tools manufactured from high-speed steel, 2nd International conference on heat treatment and surface engineering of tools and dies, May 25-28th, Bled, Slovenia, pp. $89-90$

Bárta, J. (2010). Welding of special treated thin steel sheets: Dissertation thesis, Trnava, 2010

Dománková, M.; Kebísková, J.; Lazar, R. \& Kusý, M. (2011). Influence of nitridation and nitrooxidation processes on microstructure and corrosion properties of low carbon deepdrawing steels, Materials Science and Technology [online], ISSN 1335-9053, Vol. 11, No. 1, pp. 40-51

Marônek, M.; Bárta, J.; Bártová, K. \& Dř́mal, D. (2011). Welding of steel sheets treated by nitrooxidation, JOM-16 : 16-th International Conference On the Joining of Materials \& 7-th International Conference on Education in Welding ICEW-7, May 10-13th, Tisvildeleje, Denmark, ISBN 8789582-19-5

Michalec, I.; Jančár, J. \& Marônek, M. (2010). Metallurgical joining of steel sheets treated by nitrooxidation by a hybrid CMT - laser process, 20th Anniversary International Conference on Metallurgy and Materials, May 18-20th, Brno, Czech Republic, ISBN 978-80-87294-22-2

Michalčaková, A. (2011). Plasma arc welding of steel sheets treated by nitrooxidation, Diploma thesis, Trnava, 2011 